\title{
Topoisomerase II alpha and TLE3 as predictive markers of response to anthracycline and taxane-containing regimens for neoadjuvant chemotherapy in breast cancer
}

\author{
This article was published in the following Dove Press journal: \\ OncoTargets and Therapy \\ 17 November 2014 \\ Number of times this article has been viewed
}

\author{
Tommaso Susini' \\ Barbara Bertil \\ Carlo Carriero' \\ Ketty Tavella ${ }^{2}$ \\ Jacopo Nori ${ }^{3}$ \\ Ermanno Vanzi ${ }^{3}$ \\ Cecilia Molino' \\ Mariarosaria Di Tommaso' \\ Marco Santini' \\ Valeria Saladino ${ }^{4}$ \\ Simonetta Bianchi ${ }^{4}$ \\ 'Department of Health Science, \\ Gynecology Section, ${ }^{2}$ Department \\ of Health Science, Chemotherapy \\ Section, University of Florence, Italy; \\ ${ }^{3}$ Diagnostic Senology Unit, Azienda \\ Ospedaliera-Universitaria Careggi, \\ Florence, Italy; ${ }^{4}$ Department of \\ Surgery and Translational Medicine, \\ Pathology Unit, University of \\ Florence, Italy
}

\begin{abstract}
Purpose: Anthracyclines and taxanes are considered the standard for neoadjuvant chemotherapy of breast cancer, although they are often associated with serious side effects and wide variability of individual response. In this study, we analyzed the value of topoisomerase II alpha (TOP2A) and transducin-like enhancer of split 3 (TLE3) as predictive markers of response to therapy with anthracyclines and taxanes.
\end{abstract}

Materials and methods: TOP2A and TLE3 protein expressions were evaluated using immunohistochemistry on 28 samples, obtained by core needle biopsy in patients with locally advanced breast carcinoma, subsequently subjected to epirubicin- and paclitaxel-based neoadjuvant chemotherapy. The immunohistochemical staining was correlated with the clinical response measured by the tumor size reduction evaluated by breast magnetic resonance imaging, prior and after chemotherapy, and by pathologic evaluation of the surgical specimen.

Results: Neoadjuvant chemotherapy achieved a size reduction in 26/28 tumors (92.9\%), with an average percentage decrease of $45.6 \%$. A downstaging was achieved in $71.4 \%$ of the cases of locally advanced carcinoma. TOP2A positivity was correlated with a greater reduction in tumor diameter $(P=0.06)$; negative staining for TLE3 was predictive of a better response to neoadjuvant chemotherapy $(P=0.07)$. A higher reduction in tumor diameter $(P=0.03)$ was also found for tumors that were concurrently TLE3-negative and TOP2A-positive.

Conclusion: TOP2A and TLE3 showed a correlation with response to neoadjuvant chemotherapy. While TOP2A is a well-known marker of response to anthracyclines-based chemotherapy, TLE3 is a new putative predictor of response to taxanes. Data from the current study suggest that TOP2A and TLE3 warrant further investigation in a larger series as predictors of response to neoadjuvant chemotherapy for locally advanced breast carcinoma.

Keywords: breast carcinoma, advanced stage disease, immunohistochemical markers

\section{Introduction}

Anthracyclines and taxanes are currently considered the gold standard for neoadjuvant chemotherapy of locally advanced breast cancer. However, preoperative treatment with these drugs may be associated with different degrees of response and sometimes with severe side effects. Taking into consideration the biological heterogeneity of breast cancer, which results in a wide variability of response, research has been focused on the identification of markers for prediction of the efficacy of chemotherapy based on such drugs, so that only the patients who can get benefit are subjected to the treatment.
Correspondence:Tommaso Susini Department of Health Science, Gynecology Section, University of Florence, Largo Brambilla 3, 50134 Firenze, Italy

Tel +39055275 1752

Email tommaso.susini@unifi.it 
Human epidermal growth factor receptor 2 (HER2) gene amplification and/or HER2 overexpression have been identified as predictive markers of response to anthracycline-based chemotherapy. ${ }^{1,2}$ However, their role is still controversial.

Topoisomerase II alpha (TOP2A), encoded by a gene located on chromosome 17q12-q21, plays an essential function in cell proliferation by controlling the topological state and replication of deoxyribose nucleic acid (DNA). ${ }^{3}$ Following the identification of TOP2A as the enzyme that produces the damage on $\mathrm{DNA}^{4,5}$ caused by anthracyclines, the focus has shifted on the study of the predictive value of TOP2A gene. Several studies suggested that the addition of anthracyclines in the treatment of breast cancer that showed amplification and/or deletion of TOP2A gene was associated with a better response to the therapy. ${ }^{6-10}$ The predictive role of TOP2A was also consistent with that of HER2, given the close localization of the two genes on chromosome 17. The study of Konecny et al reported that the benefits of anthracycline treatment were confined to the group of HER2positive tumors with concomitant amplification of TOP2A gene, thus demonstrating that TOP2A was more accurate as predictive marker than HER2. ${ }^{11}$ However, as the target of anthracyclines is the TOP2A protein and not the gene, and considering the poor correlation between gene amplification and overexpression of the protein, the levels of expression of the protein TOP2A have been hypothesized as even more precise markers. ${ }^{12}$

Despite numerous studies on this subject, no final verdict has been reached yet regarding the predictive role of TOP $2 \mathrm{~A}$. Thus, the first objective of this study was to further analyze the predictive value of TOP2A protein.

The association of taxanes with anthracyclines has proved a more effective treatment regimen when compared to anthracycline monotherapy associated with a higher percentage of pathological complete response (pCR) and conservative interventions. ${ }^{13}$ Taxanes cause apoptosis of tumor cells by stabilizing microtubules and inducing blockage in the $\mathrm{G} 2 / \mathrm{M}$ phase of the cell cycle. ${ }^{14}$ Over the last years, various clinical and pathologic parameters were analyzed to identify a parameter as a predictor of response to taxanes; among these, the focus was concentrated on protein Tau ${ }^{15}$ and, recently, on transducin-like enhancer of split 3 (TLE3).

The TLE3 is a member of the family of the transducinlike enhancer of split, and is a transcriptional repressor homolog of the protein Groucho, which is a part of the Notch signaling cascade in Drosophila melanogaster ${ }^{16}$ that appears to be expressed periodically during the M phase of the cell cycle. ${ }^{17}$ The Notch signaling pathway controls the cellular interactions important for the differentiation target of many cells, prolonging the state of immature precursors until the correct morphogenetic signals, necessary for cell differentiation, are available. The TLE family proteins are part of the Notch signaling pathway in mammals, and TLE genes are coexpressed with Notch genes in immature proliferative cells, thus confirming their role in the process of cell differentiation. ${ }^{18,19}$

TLE3 protein interacts directly with chromatin and chromatin-associated proteins, and it has been hypothesized to be a marker able to identify the cells that are particularly sensitive to taxane-mediated cell death. ${ }^{20,21}$

Up to date no biomarker of response to taxane chemotherapy has been validated and introduced into clinical practice. The prognostic value of TLE3 in breast cancer has been analyzed so far in a single study, which suggested the association with a higher sensitivity to taxanes. ${ }^{21}$ Similar results have been published in non-small-cell lung cancer. ${ }^{22}$ Therefore, the second goal of our study was to explore the predictive role of TLE3 protein expression in the neoadjuvant setting.

\section{Materials and methods Patients}

The study analyzed a group of 25 patients, treated in the period between December 2005 and December 2012 at the Breast Unit of the Department of Sciences for Woman's and Child's Health, University of Florence, suffering from locally advanced breast carcinoma or inflammatory cancer and initially candidates for mastectomy. Three of the patients had bilateral disease; therefore, the study was based on the analysis of 28 cases of breast cancer. All the patients gave informed consent to the use of part of their biological specimens for research purposes. The study was approved by the local ethics committee.

The clinical and pathological characteristics of the patients are summarized in Table 1.

\section{Treatment regimes}

All the patients were subjected to a median number of four cycles of neoadjuvant chemotherapy (range two to eight cycles), administered every 21 days, containing epirubicin $\left(75 \mathrm{mg} / \mathrm{m}^{2}\right)$ and paclitaxel $\left(175 \mathrm{mg} / \mathrm{m}^{2}\right)$.

Before the start of neoadjuvant therapy, the patients underwent imaging studies, including breast ultrasound, mammography, and contrast-enhanced breast magnetic resonance imaging (MRI), to obtain an accurate evaluation of tumors, with special regard to size and distribution of the lesions. 
Table I Clinical and pathologic characteristics of the patients

\begin{tabular}{|c|c|c|}
\hline Characteristic & Number & $\%$ \\
\hline Number of patients & 28 & 100.0 \\
\hline \multicolumn{3}{|l|}{ Age (years) } \\
\hline$<50$ & 18 & 64.3 \\
\hline$\geq 50$ & 10 & 35.7 \\
\hline \multicolumn{3}{|l|}{ Clinical $(T)$ stage } \\
\hline $\mathrm{T} 2$ & 15 & 53.6 \\
\hline $\mathrm{T} 3$ & 6 & 21.4 \\
\hline T4d & 7 & 25.0 \\
\hline \multicolumn{3}{|l|}{ LVSI } \\
\hline Negative & 12 & 42.9 \\
\hline Positive & 16 & 27.1 \\
\hline \multicolumn{3}{|l|}{ Type of lesion } \\
\hline Unifocal & 9 & 32.1 \\
\hline Multifocal & 10 & 45.8 \\
\hline Multifocal and multicentric & 9 & 32.1 \\
\hline \multicolumn{3}{|l|}{ Grade } \\
\hline I & 5 & 17.9 \\
\hline 2 & 9 & 32.1 \\
\hline 3 & 14 & 50.0 \\
\hline \multicolumn{3}{|l|}{ Tumor size before CTX } \\
\hline 20-30 mm & 13 & 46.4 \\
\hline $3 \mathrm{I}-50 \mathrm{~mm}$ & 4 & 14.4 \\
\hline$>50 \mathrm{~mm}$ & 11 & 39.2 \\
\hline \multicolumn{3}{|l|}{ Pathological (ypT) stage } \\
\hline урт0 & 2 & 7.1 \\
\hline урТІ & 10 & 35.7 \\
\hline урТ2 & 11 & 39.3 \\
\hline урТ3 & 1 & 3.6 \\
\hline урТ4 & 4 & 14.3 \\
\hline \multicolumn{3}{|l|}{ Tumor histology } \\
\hline Ductal & 12 & 42.9 \\
\hline Lobular & 10 & 35.7 \\
\hline Mixed & 3 & 10.7 \\
\hline Other & 3 & 10.7 \\
\hline \multicolumn{3}{|l|}{ ER status } \\
\hline Negative & 7 & 25.0 \\
\hline Positive & 21 & 75.0 \\
\hline \multicolumn{3}{|l|}{ PgR status } \\
\hline Negative & 8 & 28.6 \\
\hline Positive & 20 & 71.4 \\
\hline \multicolumn{3}{|l|}{ HER2 status } \\
\hline Negative & 23 & 82.1 \\
\hline Positive & 5 & 17.9 \\
\hline \multicolumn{3}{|l|}{ Ki-67 } \\
\hline$<15 \%$ & 11 & 39.3 \\
\hline$\geq 15 \%$ & 17 & 60.7 \\
\hline$<50 \%$ & 21 & 75.0 \\
\hline$\geq 50 \%$ & 7 & 25.0 \\
\hline
\end{tabular}

Abbreviations: CTX, chemotherapy; ER, estrogen receptor; HER2, human epidermal growth factor receptor 2; LVSI, lymphovascular space invasion; PgR, progesterone receptor.

After the last chemotherapy cycle, all imaging studies were repeated to assess the response to neoadjuvant treatment in terms of reduction in tumor diameter. Then, a conservative surgical intervention or a mastectomy was planned, according to the extent of response to neoadjuvant therapy and the breast size, as usual.

\section{Immunohistochemistry}

Before the start of neoadjuvant therapy, tumor samples were obtained by core needle biopsy for diagnostic and research purposes; the samples were then fixed in formalin and embedded in paraffin, and then subjected to routine hematoxylin and eosin staining as well as to immunohistochemical (IHC) staining.

In four cases, paraffin-embedded tissue blocks, obtained prior to chemotherapy treatment, were not available. Therefore, IHC evaluation of the expression of TOP2A and TLE3 was carried out in 24 cases.

The TOP2A protein expression was evaluated using the mouse monoclonal antibody clone 3F6 (Santa Cruz Biotechnology Inc., Dallas, TX, USA) at a dilution of 1:50, following the instructions provided by the manufacturer. The number of stained nuclei in a total of 100 cells was then counted under a microscope, and the result was expressed as a percentage of positive cells.

Thus, a cut-off of $30 \%$, corresponding to the median value of expression of TOP2A, was then chosen to define TOP2Apositive $(\geq 30 \%)$ and TOP2A-negative $(<30 \%)$ tumors (Figure 1). By this way, patients with TOP2A expression above the median of the study population were compared with those with lower immunostaining level.

The expression of TLE3 was evaluated by IHC staining with a rabbit polyclonal antibody (Santa Cruz Biotechnology) diluted to 1:200 following the instructions provided by the manufacturer. The count of stained nuclei was done and scored as previously described. In this case, after exploring different cut-off values, the cut-off value was chosen arbitrarily as negative versus positive (any staining) (Figure 2). The choice has been made in pursuit of optimization of the correlation between TLE3 protein expression and response to chemotherapy in terms of size reduction of the tumor.

\section{Statistical analysis}

The response to neoadjuvant chemotherapy was evaluated in terms of percentage of the reduction in tumor size by measuring the largest diameter of the tumor before and after neoadjuvant therapy, using the information obtained from imaging techniques: ultrasound, mammography, and MRI. The final size of the tumor was measured by the pathologist on the surgical specimen.

The clinical outcome was evaluated by measuring the disease-free survival, defined as the time elapsed from the beginning of neoadjuvant therapy up to the date on which the development of a recurrence of cancer, both local or distant, was recorded, or the date of last follow-up visit. 


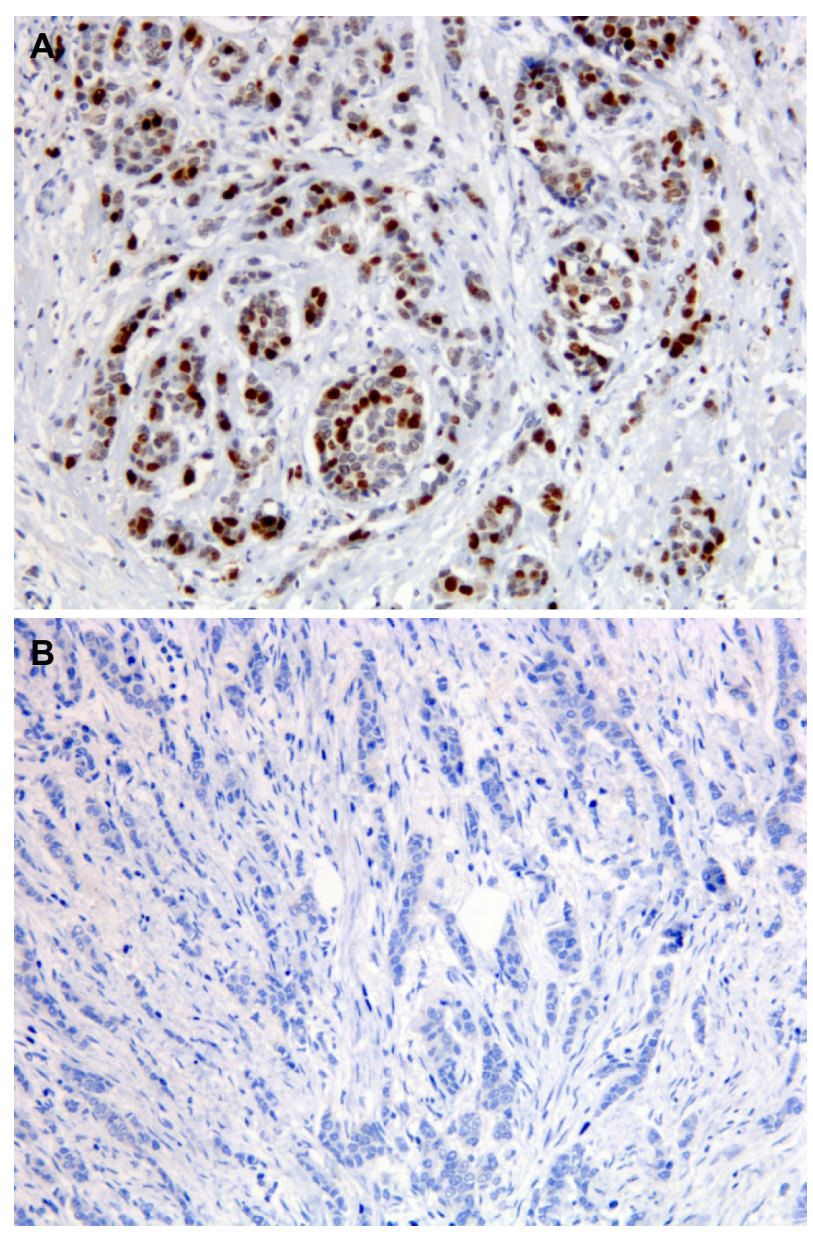

Figure I Immunostaining for TOP2A in preoperative breast cancer core biopsies. Note: Staining was $(\mathbf{A})$ positive $(\geq 30 \%$ positivity) $(\times 200)$ or $(\mathbf{B})$ negative $(<30 \%$ positivity) $(\times 200)$.

Abbreviation: TOP2A, topoisomerase II alpha.

The median follow-up of patients was 36 months (range 12-103).

The frequency distribution of the studied parameters among the population was assessed by Fisher's exact test or by chi-square test, as appropriate. The association of each variable with the reduction in tumor size was estimated by means of logistic regression. The disease-free survival was calculated according to the Kaplan-Meier method, and the differences were evaluated using the log-rank test.

All the statistical analyses were performed using IBM Statistical Package for the Social Sciences software, version 21 .

\section{Results}

Comparing the data obtained by imaging techniques before and after neoadjuvant chemotherapy with the pathological information from the surgical specimen, a reduction in tumor size was achieved in 26 of 28 cases $(92.9 \%)$. The average

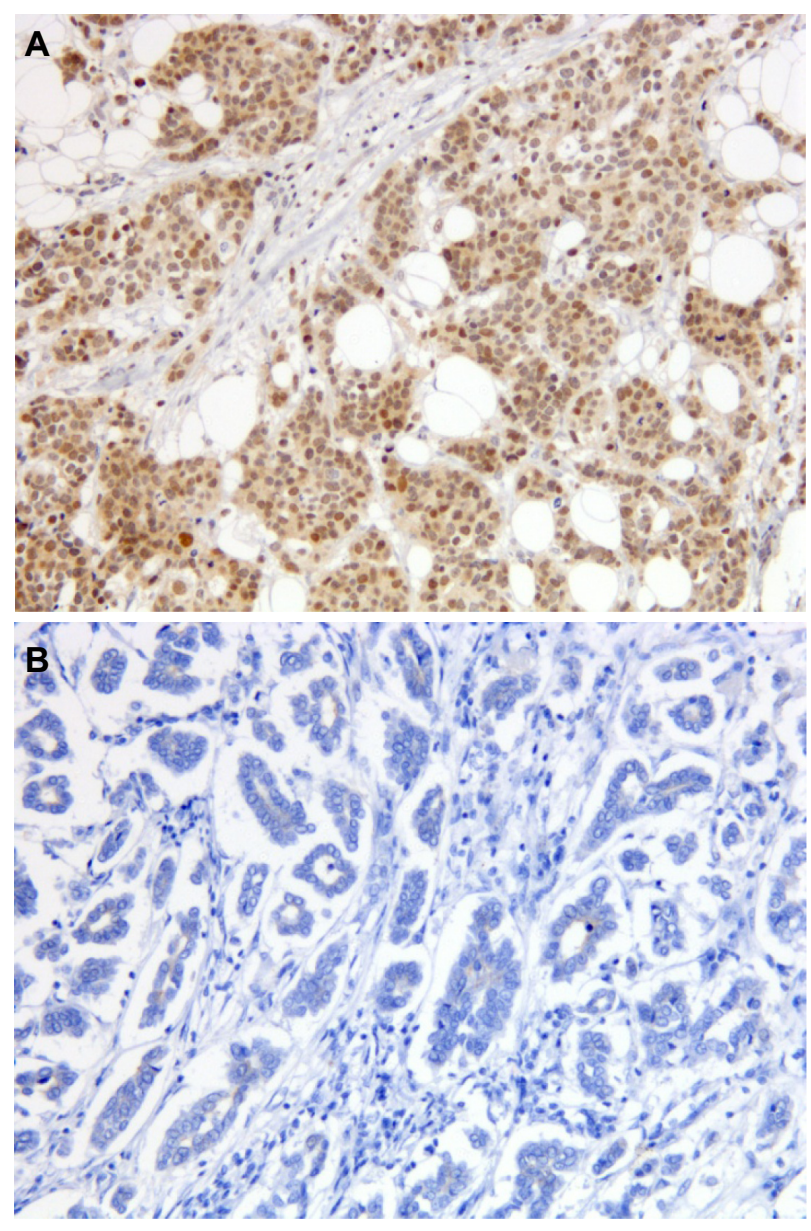

Figure 2 Immunostaining for TLE3 in preoperative breast cancer core biopsies. Note: Staining was $(\mathbf{A})$ positive ( $\geq 1 \%$ positivity) $(\times 200)$ or $(\mathbf{B})$ negative (null positivity) $(\times 200)$.

Abbreviation: TLE3, transducin-like enhancer of split 3.

size of tumors prior to chemotherapy treatment was $49.5 \mathrm{~mm}$, while after the therapy $25.7 \mathrm{~mm}$ (Table 2), with an average percentage reduction by $45.6 \%$.

In two cases (7.2\%), a complete pathologic response (pCR) was achieved, evidenced by preoperative MRI and confirmed by histologic evaluation of the surgical specimen. The distribution of the cases according to percentage of size reduction is given in detail in Table 3 .

Table 2 Tumor diameter before and after neoadjuvant chemotherapy treatment

\begin{tabular}{llllll}
\hline $\begin{array}{l}\text { Tumor } \\
\text { size }(\mathbf{m m})\end{array}$ & \multicolumn{2}{l}{ Before CTX } & & & After CTX \\
\cline { 2 - 3 } & Number & $\%$ & & Number & $\%$ \\
\hline $0-19$ & - & - & 10 & 35.6 \\
$20-30$ & 13 & 46.4 & & 10 & 35.6 \\
$31-50$ & 4 & 14.4 & & 5 & 18.0 \\
$>50$ & $1 \mathrm{I}$ & 39.2 & & 3 & 10.8 \\
\hline
\end{tabular}

Abbreviation: CTX, chemotherapy. 
Table 3 Distribution by size reduction (\%) after chemotherapy treatment

\begin{tabular}{lll}
\hline Size reduction (\%) & Number & $\%$ \\
\hline $0-19$ & 3 & 10.7 \\
$20-49$ & 13 & 46.4 \\
$50-69$ & 6 & 21.4 \\
$70-99$ & 4 & 14.3 \\
100 & 2 & 7.2 \\
\hline
\end{tabular}

In seven cases, the indication for neoadjuvant chemotherapy was represented by inflammatory breast carcinoma. All these cases underwent mastectomy, irrespective of the degree of response. Among the remaining 21 cases with locally advanced breast carcinoma, downstaging of the tumor was obtained in 15 of 21 cases (71.4\%). So, after neoadjuvant chemotherapy, a breast conserving procedure was performed in 15 of 21 cases $(71.4 \%)$.

By IHC, the average TOP2A protein expression was $41 \%$ (standard deviation $[\mathrm{SD}]=26.4 \%$ ), with a median of $30 \%$. Considering the median value as cut-off, we had eight TOP2A-negative cases (33.3\%) and 16 TOP2A-positive cases $(66.6 \%)$.

The average expression of TLE3 protein was $49 \%$ ( $\mathrm{SD}=32.0 \%$ ), with a median of $55 \%$. We had three TLE3negative cases (12.5\%) and 21 TLE3-positive cases $(87.5 \%)$.

To investigate the possible correlation between the IHC expression of TOP2A and TLE3 and response to neoadjuvant chemotherapy, taking into consideration that the average size reduction was $45.6 \%$, we arbitrarily considered patients with size reduction $\geq 70 \%$ as good responders. Overall, $21.4 \%$ of the patients $(6 / 28)$ were good responders, while $78.6 \%$ $(22 / 28)$ obtained a reduction in tumor diameter $<70 \%$.

To evaluate the predictive value of clinicopathological and IHC characteristics of tumors in the identification of good responders, a logistic regression analysis was carried out (Table 4).

Tumors with very low expression of progesterone receptor $(\mathrm{PgR}<10 \%)(P=0.04)$ and those with low expression of estrogen receptor (ER $<70 \%)(P=0.05)$ were associated with an increased sensitivity to neoadjuvant chemotherapy. Age was a predictive factor, in that patients $\geq 50$ years old had a better response to therapy $(P=0.01)$. TOP $2 \mathrm{~A}$ positivity $(\geq 30 \%)$ and TLE3 negativity were also associated with a marked response to neoadjuvant chemotherapy $(P=0.06$ and $P=0.07$, respectively).

More detailed analysis of the association between TOP2A immunostaining with the extent of response to neoadjuvant chemotherapy showed that $100 \%$ of good responders
Table 4 Probability to obtain a tumor size reduction $\geq 70 \%$ after neoadjuvant chemotherapy according to clinical-pathological and IHC features (logistic regression analysis)

\begin{tabular}{|c|c|c|c|}
\hline \multirow[t]{2}{*}{ Characteristic } & \multicolumn{3}{|c|}{ Size reduction $\geq \mathbf{7 0} \%$} \\
\hline & HR & $95 \% \mathrm{Cl}$ & $P$-value \\
\hline \multicolumn{4}{|l|}{ Age (years) } \\
\hline$<50$ & I & & \\
\hline$\geq 50$ & 17.0 & $1.59-181.36$ & 0.01 \\
\hline \multicolumn{4}{|l|}{ ER (\%) } \\
\hline$<70$ & I & & \\
\hline$\geq 70$ & 0.14 & $0.02-1.05$ & 0.05 \\
\hline \multicolumn{4}{|l|}{$\operatorname{PgR}(\%)$} \\
\hline$<10$ & I & & \\
\hline$\geq 10$ & 0.09 & $0.009-0.95$ & 0.04 \\
\hline \multicolumn{4}{|l|}{ TLE3 } \\
\hline Positive & I & & \\
\hline Negative & 12.5 & $0.8 I-166.66$ & 0.07 \\
\hline \multicolumn{4}{|l|}{ TOP2A } \\
\hline Negative & I & & \\
\hline Positive & 9.0 & $0.88-91.25$ & 0.06 \\
\hline \multicolumn{4}{|l|}{ Ki-67 } \\
\hline$<50 \%$ & I & & \\
\hline$\geq 50 \%$ & 4.50 & $0.65-31.08$ & 0.12 \\
\hline \multicolumn{4}{|l|}{ HER2 } \\
\hline Negative & 1 & & \\
\hline Positive & 0.90 & $0.08-9.97$ & 0.93 \\
\hline \multicolumn{4}{|l|}{ Triple-negative } \\
\hline No & I & & \\
\hline Yes & 3.16 & $0.39-25.57$ & 0.27 \\
\hline \multicolumn{4}{|l|}{ Grade } \\
\hline $\mathrm{I}-2$ & 1 & & \\
\hline 3 & 2.40 & $0.36-15.94$ & 0.36 \\
\hline \multicolumn{4}{|c|}{ Pathological (ypT) stage } \\
\hline $\mathrm{T} 2$ & 1 & & \\
\hline T3-T4 & 3.16 & $0.39-25.57$ & 0.27 \\
\hline \multicolumn{4}{|l|}{ LVSI } \\
\hline Negative & I & & \\
\hline Positive & 0.28 & $0.04-1.92$ & 0.19 \\
\hline \multicolumn{4}{|l|}{ Type of lesion } \\
\hline Not multicentric & I & & \\
\hline Multicentric & 3.21 & $0.43-23.78$ & 0.25 \\
\hline \multicolumn{4}{|l|}{ Tumor histology } \\
\hline Ductal & I & & \\
\hline Others & 0.28 & $0.04-1.92$ & 0.19 \\
\hline
\end{tabular}

Abbreviations: $\mathrm{Cl}$, confidence interval; $\mathrm{ER}$, estrogen receptor; HER2, human epidermal growth factor receptor 2; HR, hazard ratio; LVSI, lymphovascular space invasion; PgR, progesterone receptor; TLE3, transducin-like enhancer of split 3; TOP2A, topoisomerase II alpha.

(reduction $\geq 70 \%$ ) were TOP2A-positive, while among those who did not get such reduction, 58\% (11/19) were TOP2Apositive $(P=0.1)$. None of the TOP2A-negative patients achieved a marked response to chemotherapy (Figure 3).

TOP2A positivity was associated with a trend to show a better outcome in terms of disease-free survival $(P=0.3)$ (Figure 4). 


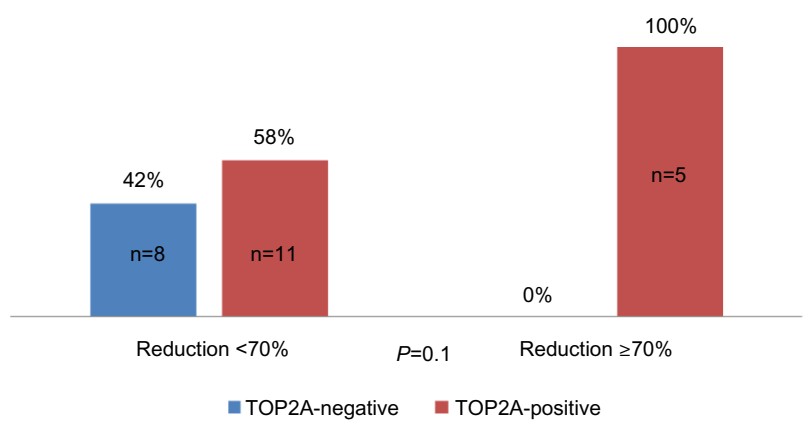

Figure 3 Distribution of good responders according toTOP2A status. Abbreviation: TOP2A, topoisomerase II alpha.

Analysis of the TLE3 expression revealed that among good responder patients, 40\% were TLE3-negative, in comparison with only $5 \%$ who did not achieve such a reduction $(P=0.09)$ (Figure 5).

Finally, considering the subgroup of patients who were concurrently TOP2A-positive and TLE3-negative $(n=2)$, all of them were good responder patients $(P=0.03)$ (Figure 6) and were disease free at the end of follow-up period (Figure 7). Concerning the clinical outcome, the results confirmed the association between response to neoadjuvant chemotherapy resulting in downstaging of the tumor and disease-free survival. In fact, patients with ypT1-T2 disease behaved significantly better than those with ypT3-T4 stage disease after neoadjuvant treatment $(P<0.001)$ (Figure 8).

\section{Discussion}

Our study confirmed the efficacy of epirubicin- and paclitaxel-based neoadjuvant chemotherapy regimen in

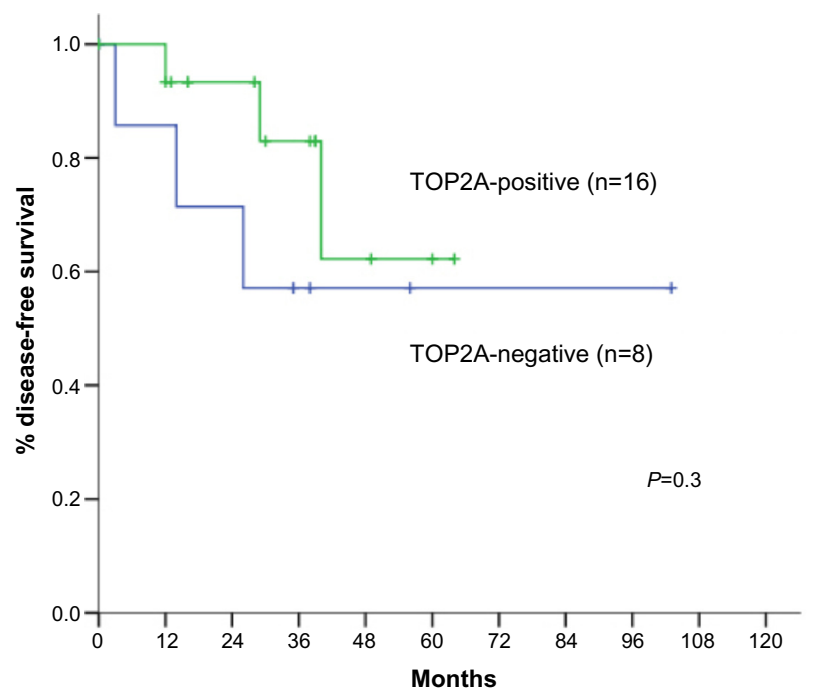

Figure 4 Disease-free survival according to TOP2A positivity. Abbreviation: TOP2A, topoisomerase II alpha.

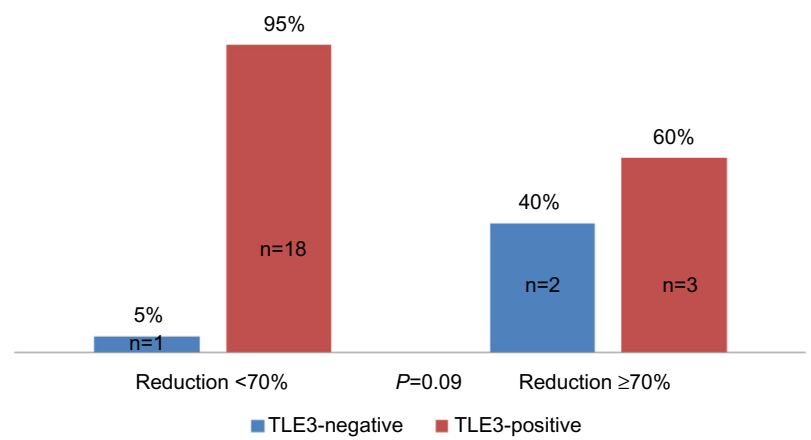

Figure 5 Distribution of good responders according to TLE3 status. Abbreviation: TLE3, transducin-like enhancer of split 3.

patients with locally advanced breast cancer, showing a reduction in tumor volume in almost all cases (26 out of 28 patients, $92.9 \%$ ), with an average size reduction by almost half $(45.6 \%)$ (Table 3$){ }^{23}$

Excluding cases of inflammatory breast cancer, the downstaging was obtained in $71.4 \%$ of cases ( 15 out of 21 patients). The marked reduction in tumor size after neoadjuvant chemotherapy resulting in downstaging confirmed its strong impact on clinical outcome (Figure 8). In addition, taking into consideration that before neoadjuvant chemotherapy all the patients were candidates for a mastectomy, this result has allowed sparing of mastectomy in favor of a breast conserving procedure in $71.4 \%$ of our patients. In agreement with our data, in the literature, there are several studies demonstrating the efficacy of preoperative chemotherapy in reducing tumor size and, consequently, in reducing mutilating interventions in favor of more conservative procedures, such as quadrantectomy or tumorectomy. ${ }^{23-26}$

In the current series, we obtained a pCR in $7.1 \%$ of the patients $(9.5 \%$ if we exclude patients with initial diagnosis of carcinomatous mastitis). Percentages of pCR following neoadjuvant chemotherapy for locally advanced breast cancer

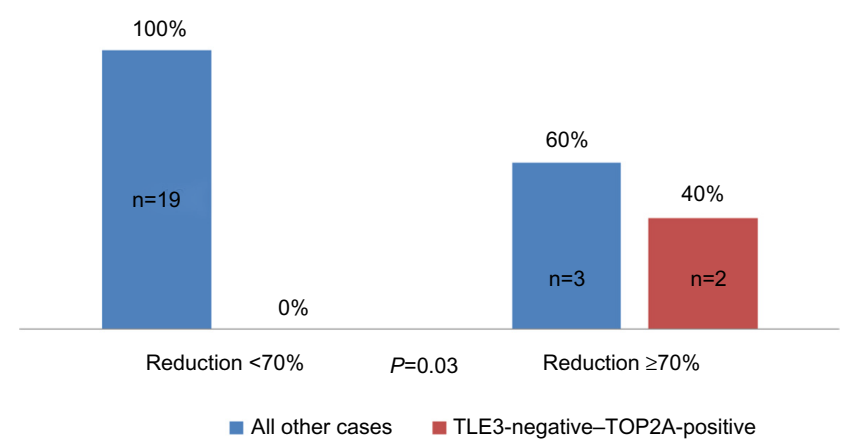

Figure 6 Distribution of good responders according to concurrent TOP2A positivity and TLE3 negativity.

Abbreviations: TLE3, transducin-like enhancer of split 3; TOP2A, topoisomerase Il alpha. 


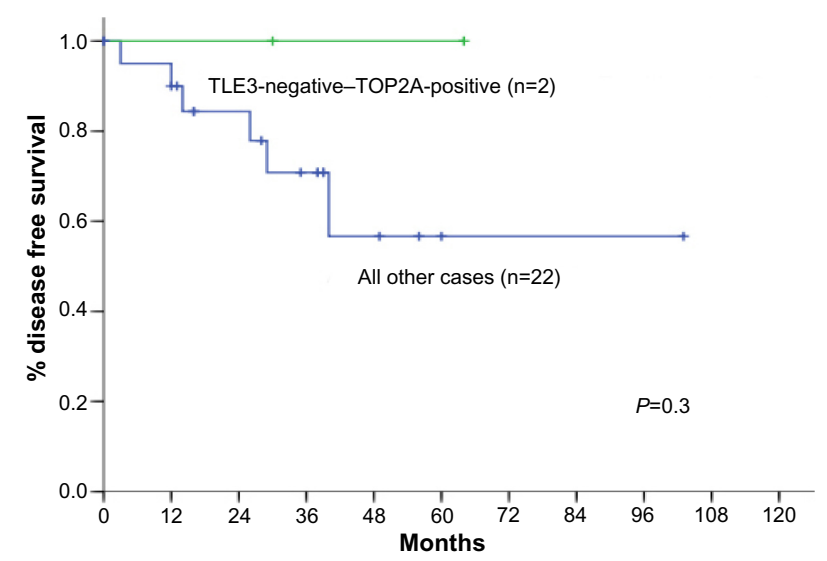

Figure 7 Disease-free survival estimates for patients with concurrent TOP2Apositive and TLE3-negative tumors, in comparison with all other patients. Abbreviations: TLE3, transducin-like enhancer of split 3; TOP2A, topoisomerase II alpha.

reported in the literature are highly variable $(4 \%-34 \%))^{25,26}$ Such variability in the rate of pCR in the literature is probably due to different criteria used to define it, the heterogeneity of breast cancer biology, and the different systemic treatments administered. The relatively low percentage of $\mathrm{pCR}$ obtained in this study could be explained by the accurate and intensive histological analysis of the surgical specimen performed by our pathologists, able to detect even minimum residual disease.

Concerning the cases of carcinomatous mastitis, the epirubicin- and paclitaxel-based regimen used in this study was effective as well, because all the patients, initially with inoperable cancer diagnosis, obtained a response allowing us at least to perform a mastectomy with axillary dissection

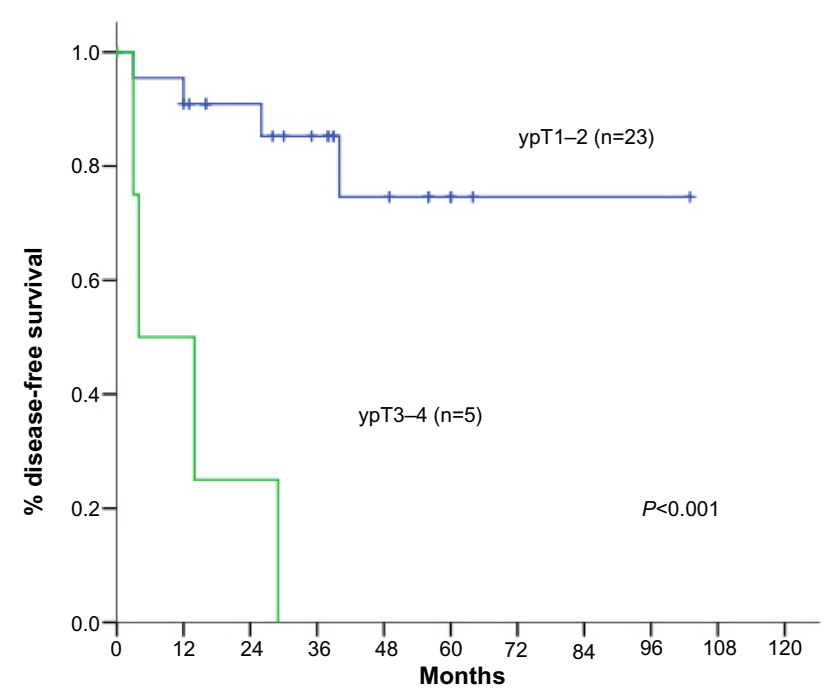

Figure 8 Disease-free survival estimates for patients with response to neoadjuvant chemotherapy, resulting in comparison of ypTI-T2 stage patients with ypT3-T4 stage patients. having clear margins. This approach to the management of carcinomatous mastitis is currently the standard. ${ }^{27-29}$

Among predictors of response to neoadjuvant chemotherapy, we found that tumors with low expression of ER and $\mathrm{PgR}$ and patients aged $>50$ years had a significantly greater likelihood of achieving a marked volume reduction in response to anthracycline- and taxane-based chemotherapy (Table 4), in agreement with previous studies. ${ }^{30}$

Concerning the role of TOP2A and TLE3, our findings were encouraging, although the results only approached statistical significance. The study searched for a correlation between the IHC expression of TOP2A and TLE3 with the reduction in tumor volume after chemotherapy and the disease-free survival. As far as TOP2A is concerned, analysis focused on the value of the expression of the TOP2A protein and not its gene amplification, as the target of anthracyclines is the protein and not the gene. Furthermore, it is well known that the relation between the amplification of TOP2A gene and the expression of TOP2A protein is poor, probably due to transcriptional and post-transcriptional protein degradation processes. ${ }^{31}$ In the current study, we found that IHC for TOP2A showed an average protein expression of $41 \%$ and a median of $30 \%$, in line with the values reported in the literature. ${ }^{32-35} \mathrm{TOP} 2 \mathrm{~A}$ positivity was associated with a nine-fold higher probability to obtain a good response (decrease in size $\geq 70 \%$ ) (Table 4 ), although this result was of borderline statistical significance $(P=0.06)$. In particular, all the patients who achieved a marked reduction in tumor size ( $\geq 70 \%$ ) were TOP2A-positive; by contrast, none of the TOP2A-negative patients achieved a marked response to chemotherapy (Figure 3). This result, however, was not statistically significant, possibly because of the low number of cases analyzed. In the literature, the studies that evaluated the role of TOP2A as predictor of response to neoadjuvant chemotherapy with anthracyclines provided heterogeneous result: in fact, some studies showed that the overexpression of TOP2A predicts a good clinical response to chemotherapy, ${ }^{33}$ while others failed to demonstrate this correlation. ${ }^{34}$

In our study, we have identified a correlation between the overexpression of TOP2A and response to the therapy with anthracyclines in terms of reduction in tumor volume $\geq 70 \%$. Our data suggest that TOP2A positivity, although indicating more likely to respond, does not confer the certainty of getting a good response (reduction $\geq 70 \%$ ) to neoadjuvant chemotherapy based on anthracyclines. On the other hand, the negativity of TOP2A was associated with the lack of response. These results are in line with other studies claiming that a decrease in expression of TOP2A protein confers resistance to anthracyclines. ${ }^{35}$ 
Concerning clinical outcome, patients with TOP2A positivity showed a trend to develop fewer recurrences and to have a prolonged disease-free survival. However, the difference was not statistically significant in our data set, probably due to the low number of cases (Figure 4). Also in this case, the data reported in the literature are contradictory, with some clinical studies showing improved outcome after addiction of anthracyclines in TOP2A-positive patients, ${ }^{36}$ while others negate this. ${ }^{37}$

Concerning TLE3, which was hypothesized as a possible marker of response to taxane-based chemotherapy, there are very few data in the literature. In our study, the average expression of the TLE3 protein was 49\% (median 55\%). We found a correlation between TLE3 negativity and good response to therapy. Hence, a reduction of tumor size $\geq 70 \%$ was likely to occur 12-fold more frequently among TLE3negative cases (Table 4$)$. However, this result only approached statistical significance $(P=0.07)$.

More in detail, two-thirds of TLE3-negative patients achieved a marked response to chemotherapy, while only $14.2 \%$ of the TLE3-positive patients got such response (Figure 5). Also in this case, the results suggest that TLE3 negativity does not confer the certainty of obtaining a high response to neoadjuvant chemotherapy, and TLE3 positivity predicts that, with high probability $(85.8 \%)$, the patient will not get a marked size reduction. The limited number of cases in the study and especially the small sample of cases with TLE3-negative tumors greatly reduce the strength of our observations.

There is only one previous report on the expression of TLE3 as predictive marker of response to neoadjuvant chemotherapy with taxanes. That study was carried out by Kulkarni et al on a sample of 411 breast cancer patients, and they reported results in conflict with ours. ${ }^{21}$ In fact, they found that TLE3-positive tumors (IHC expression $\geq 30 \%$ ) were associated with a greater reduction in tumor diameter, with a lower risk of recurrence after neoadjuvant chemotherapy, and with a better disease-free survival. It must be noted, however, that in the study of Kulkarni et al, only 23 patients received neoadjuvant chemotherapy as our cases, whereas the majority of the cases in their study did not. Therefore their results were not comparable with ours. Explanation for these conflicting results may be sought in the different types of antibody used for IHC analysis and/or the lack of a sufficiently standardized procedure for the allocation of the labeling percentage. Both our study and that of Kulkarni et $\mathrm{a}^{21}$ are based on a limited number of cases with neoadjuvant chemotherapy, which makes it impossible to draw definitive conclusions.
We also tried to combine the predictive value of TOP2A and TLE3. Considering the group of patients with tumors that were concurrently TLE3-negative and TOP2A-positive, we found that all the patients with such characteristics were good responders to neoadjuvant chemotherapy (reduction in size $\geq 70 \%$ ) (Figure 6 ), whereas only $13.6 \%$ of patients without these characteristics got a marked response to neoadjuvant chemotherapy $(P=0.03)$. Similarly, all the patients with TLE3-negative and TOP2A-positive tumors were disease free at 5-years follow-up, in contrast with a disease-free survival of only $58 \%$ for all the other patients (Figure 8 ). This result was very intriguing. However, because the number of cases with TLE3-negative and TOP2A-positive tumors was very little in the current study ( $\mathrm{n}=2,8.3 \%)$, this finding should be interpreted with caution. All together, these results suggest that immunostaining for TOP2A and TLE3 may provide useful information as predictive markers of response to neoadjuvant chemotherapy based on anthracyclines and taxanes. The possible role of concomitant TLE3 negativity and TOP2A positivity as predictor of response to neoadjuvant chemotherapy in breast carcinoma warrants further investigation in a larger series.

\section{Conclusion}

This mono-institutional study showed that TOP2A positivity and TLE3 negativity were both associated with a better response to neoadjuvant chemotherapy based on anthracyclines and taxanes. These IHC characteristics, especially when concurrently present, correlated to a better outcome too. However, probably because of a relatively small number of patients, statistical significance was not always achieved.

Therefore, though some evidence that emerged from our study is suggestive, our results do not support routine use of TOP2A and TLE3 as predictors of response to neoadjuvant chemotherapy with anthracyclines and taxanes. Nonetheless, considering that this was the first study that investigated the role of concomitant evaluation of TOP2A and TLE3 as markers of response to neoadjuvant chemotherapy, further studies are needed, based on larger series of patients and possibly with a multicenter approach, to provide a clear answer to the growing demand of markers useful for the personalization of neoadjuvant treatment of breast cancer.

\section{Acknowledgment}

We thank Gianna Baroni for her expert technical assistance in the IHC analysis. 


\section{Disclosure}

The authors report no conflicts of interest in this work.

\section{References}

1. Gennari A, Sormani MP, Pronzato P, et al. HER2 status and efficacy of adjuvant anthracyclines in early breast cancer: a pooled analysis of randomized trials. J Natl Cancer Inst. 2008;100(1):14-20.

2. Dhesy-Thind B, Pritchard KI, Messersmith H, O'Malley F, Elavathil L, Trudeau M. HER2/neu in systemic therapy for women with breast cancer: a systematic review. Breast Cancer Res Treat. 2008;109(2): 209-229.

3. Champoux JJ. DNA topoisomerases: structure, function, and mechanism. Аnпu Rev Biochem. 2001;70:369-413.

4. Ross WE, Glaubiger DL, Kohn KW. Protein-associated DNA breaks in cells treated with adriamycin or ellipticine. Biochim Biophys Acta. 1978;519(1):23-30.

5. Zwelling LA, Michaels S, Erickson LC, Ungerleider RS, Nichols M, Kohn KW. Protein-associated deoxyribonucleic acid strand breaks in L1210 cells treated with the deoxyribonucleic acid intercalating agents 4'-(9-acridinylamino) methanesulfon-m-anisidide and adriamycin. Biochemistry. 1981;20(23):6553-6563.

6. O’Malley FP, Chia S, Tu D, et al. Topoisomerase II alpha and responsiveness of breast cancer to adjuvant chemotherapy. J Natl Cancer Inst. 2009;101(9):644-650.

7. Di Leo A, Gancberg D, Larsimont D, et al. HER-2 amplification and topoisomerase IIalpha gene aberrations as predictive markers in node-positive breast cancer patients randomly treated either with an anthracycline-based therapy or with cyclophosphamide, methotrexate, and 5-fluorouracil. Clin Cancer Res. 2002;8(5):1107-1116.

8. Knoop AS, Knudsen H, Balslev E, et al. Retrospective analysis of topoisomerase IIa amplifications and deletions as predictive markers in primary breast cancer patients randomly assigned to cyclophosphamide, methotrexate, and fluorouracil or cyclophosphamide, epirubicin, and fluorouracil: Danish Breast Cancer Cooperative Group. J Clin Oncol. 2005;23(30):7483-7490.

9. Du Y, Zhou Q, Yin W, et al. The role of topoisomerase II $\alpha$ in predicting sensitivity to anthracyclines in breast cancer patients: a meta-analysis of published literatures. Breast Cancer Res Treat. 2011;129(3):839-848.

10. Scandinavian Breast Group Trial 9401, Tanner M, Isola J, et al. Topoisomerase IIalpha gene amplification predicts favorable treatment response to tailored and dose-escalated anthracycline-based adjuvant chemotherapy in HER-2/neu-amplified breast cancer: Scandinavian Breast Group Trial 9401. J Clin Oncol. 2006;24:2428-2436.

11. Konecny GE, Pauletti G, Untch M, et al. Association between HER2, TOP $2 \mathrm{~A}$, and response to anthracycline-based preoperative chemotherapy in high-risk primary breast cancer. Breast Cancer Res Treat. 2010;120(2):481-489.

12. Schindlbeck C, Janni W, Shabani N, et al. Isolated tumor cells in the bone marrow (ITC-BM) of breast cancer patients before and after anthracycline based therapy: influenced by the HER2- and Topoisomerase IIalpha-status of the primary tumor? J Cancer Res Clin Oncol. 2005;131(8):539-546.

13. Cuppone F, Bria E, Carlini P, et al. Taxanes as primary chemotherapy for early breast cancer: meta-analyses of randomized trials. Cancer. 2008;113(2):238-246.

14. Crown J, O'Leary M, Ooi WS. Docetaxel and paclitaxel in the treatment of breast cancer: a review of clinical experience. Oncologist. 2004;9(Suppl 2):24-32.

15. Andre F, Hatzis C, Anderson K, et al. Microtubule-associated proteintau is a bifunctional predictor of endocrine sensitivity and chemotherapy resistance in estrogen receptor-positive breast cancer. Clin Cancer Res. 2007;13(7):2061-2067.

16. Chen G, Courey AJ. Groucho/TLE family proteins and transcriptional repression. Gene. 2000;249(1-2):1-16.
17. Whitfield ML, Sherlock G, Saldanha AJ, et al. Identification of genes periodically expressed in the human cell cycle and their expression in tumors. Mol Biol Cell. 2002;13(6):1977-2000.

18. Aithal MG, Rajeswari N. Role of Notch signalling pathway in cancer and its association with DNA methylation. J Genet. 2013;92(3):667-675.

19. Espinoza I, Pochampally R, Xing F, Watabe K, Miele L. Notch signaling: targeting cancer stem cells and epithelial-to-mesenchymal transition. Onco Targets Ther. 2013;6:1249-1259.

20. Sekiya T, Zaret KS. Repression by Groucho/TLE/Grg proteins: genomic site recruitment generates compacted chromatin in vitro and impairs activator binding in vivo. Mol Cell. 2007;28(2):291-303.

21. Kulkarni SA, Hicks DG, Watroba NL, et al. TLE3 as a candidate biomarker of response to taxane therapy. Breast Cancer Res. 2009;11(2):R17.

22. Ross DT, Seitz RS, Ring BZ, et al. Abstract 3734: TLE3 expression is predictive of response to chemotherapy in NSCLC. Cancer Res. 2010;70(8 Suppl 1); Abstract nr 3734.

23. Kaya AO, Coskun U, Buyukberber S, et al. Efficacy and toxicity of preoperative chemotherapy with docetaxel and epirubicin in locally advanced invasive breast cancer. $J$ BUON. 2010;15(2):248-254 .

24. Yuan Z, Qu X, Zhang ZT, Wang Y. Neoadjuvant chemotherapy in patients with stages II and III breast cancer. Chin Med $J$ (Engl). 2009;122(24):2993-2997.

25. Charfare H, Limongelli S, Purushotham AD. Neoadjuvant chemotherapy in breast cancer. Br J Surg. 2005;92(1):14-23.

26. Wolmark N, Wang J, Mamounas E, Bryant J, Fisher B. Preoperative chemotherapy in patients with operable breast cancer: nine-year results from National Surgical Adjuvant Breast and Bowel Project B-18. Natl Cancer Inst Monogr. 2001;30:96-102.

27. Dawood S, Merajver SD, Viens P, et al. International expert panel on inflammatory breast cancer: consensus statement for standardized diagnosis and treatment. Ann Oncol. 2011;22(3):515-523.

28. Dawood S, Cristofanilli M. Inflammatory breast cancer: what progress have we made? Oncology (Williston Park). 2011;25(3):264-270; 273.

29. National Comprehensive Cancer Network Guidelines; 2014. [Homepage on the Internet]. Available from: http://www.nccn.org/patients/guidelines/stage_iv_breast/index.html\#1. Accessed September 23, 2014.

30. Berry DA, Cirrincione C, Henderson IC, et al. Estrogen-receptor status and outcomes of modern chemotherapy for patients with node-positive breast cancer. JAMA. 2006;295(14):1658-1667.

31. Kellner U, Sehested M, Jensen PB, Gieseler F, Rudolph P. Culprit and victim DNA topoisomerase II. Lancet Oncol. 2002;3(4):235-243.

32. Fountzilas G, Valavanis C, Kotoula V, et al. HER2 and TOP2A in highrisk early breast cancer patients treated with adjuvant epirubicin-based dose-dense sequential chemotherapy. J Transl Med. 2012;10:10.

33. MacGrogan G, Rudolph P, Mascarel Id I, et al. DNA topoisomerase IIalpha expression and the response to primary chemotherapy in breast cancer. Br J Cancer. 2003;89(4):666-671.

34. Petit T, Wilt M, Velten M, et al. Comparative value of tumor grade, hormonal receptors, Ki-67, HER-2 and topoisomerase II alpha status as predictive markers in breast cancer patients treated with neoadjuvant anthracycline-based chemotherapy. Eur J Cancer. 2004;40(2):205-211.

35. Mo YY, Ameiss KA, Beck WT. Overexpression of human DNA topoisomerase II alpha by fusion to enhanced green fluorescent protein. Biotechniques. 1998;25(6):1052-1057.

36. O'Malley FP, Chia S, Tu D, et al. Topoisomerase II alpha protein overexpression has predictive utility in a randomized trial comparing CMF to CEF in premenopausal women with node positive breast cancer (NCIC CTG MA.5). [Abstract]. Breast Cancer Res Treat. 2006; 100(Supp1 1):A-38; S18.

37. Durbecq V, Paesmans M, Cardoso F, et al. Topoisomerase-II alpha expression as a predictive marker in a population of advanced breast cancer patients randomly treated either with single-agent doxorubicin or single-agent docetaxel. Mol Cancer Ther. 2004;3(10): 1207-1214. 


\section{Publish your work in this journal}

OncoTargets and Therapy is an international, peer-reviewed, open access journal focusing on the pathological basis of all cancers, potential targets for therapy and treatment protocols employed to improve the management of cancer patients. The journal also focuses on the impact of management programs and new therapeutic agents and protocols on

patient perspectives such as quality of life, adherence and satisfaction. The manuscript management system is completely online and includes a very quick and fair peer-review system, which is all easy to use. Visit http://www.dovepress.com/testimonials.php to read real quotes from published authors.

Submit your manuscript here: http://www.dovepress.com/oncotargets-and-therapy-journal 